\section{NOVA TELLVS}

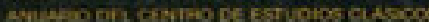

Nova Tellus

ISSN: 0185-3058

novatelu@servidor.unam.mx

Centro de Estudios Clásicos

México

MONTEMAYOR ACEVES, Martha Elena

Contenidos jurídicos en el relato de Cupido y Psique de Apuleyo

Nova Tellus, vol. 24, núm. 2, 2006, pp. 245-261

Centro de Estudios Clásicos

Distrito Federal, México

Disponible en: http://www.redalyc.org/articulo.oa?id=59120913010

Cómo citar el artículo

- Número completo

- Más información del artículo

- Página de la revista en redalyc.org

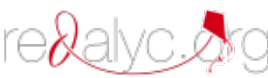

Sistema de Información Científica

Red de Revistas Científicas de América Latina, el Caribe, España y Portugal

Proyecto académico sin fines de lucro, desarrollado bajo la iniciativa de acceso abierto 


\title{
Contenidos jurídicos en el relato de Cupido y Psique de Apuleyo
}

\author{
Martha Elena Montemayor Aceves \\ Universidad Nacional Autónoma de México \\ montemayor.martha@gmail.com
}

\begin{abstract}
RESUMEN: Resulta interesante acercarse al estudio del Derecho romano, partiendo de otras fuentes no estrictamente jurídicas, como son las literarias, pues con frecuencia éstas proporcionan información acerca de los preceptos normativos de la sociedad. En este trabajo se pretende rastrear contenidos jurídicos, como las instituciones romanas del matrimonio y de la esclavitud, que se encuentran en el relato de Cupido y Psique, pieza central de la obra El asno de oro de Apuleyo, tomando en cuenta que este autor tuvo una formación, además de filosófica y literaria, en gran medida jurídica, ya que parte de su vida trabajó como abogado, presentando causas de ciudadanos e, incluso, defendiéndose a sí mismo contra una acusación por práctica de magia.
\end{abstract}

$$
* * *
$$

ABSTRACT: It is interesting to approach Roman Law from other sources non strictly legal, such as the literary ones, since they frequently provide information about standard precepts in society. In this article the aim is to look for their legal contents, such as Roman institutions concerning marriage and slavery, that are found in the story of Cupid and Psyche, the main part of The Golden Ass by Apuleius. It must be emphazised that this author devoted not only to philosophy and literary studies, but also applied himself as a lawyer part of his life, dealing with cases of particular citizens, and even defending himself against an accusation for practicing magic.

Palabras Clave: Apuleyo, Cupido, derecho romano, esclavitud, matrimonio, Psique.

RECEPCIÓN: 18 de septiembre de 2006.

ACEPTACIÓN: 13 de octubre de 2006. 


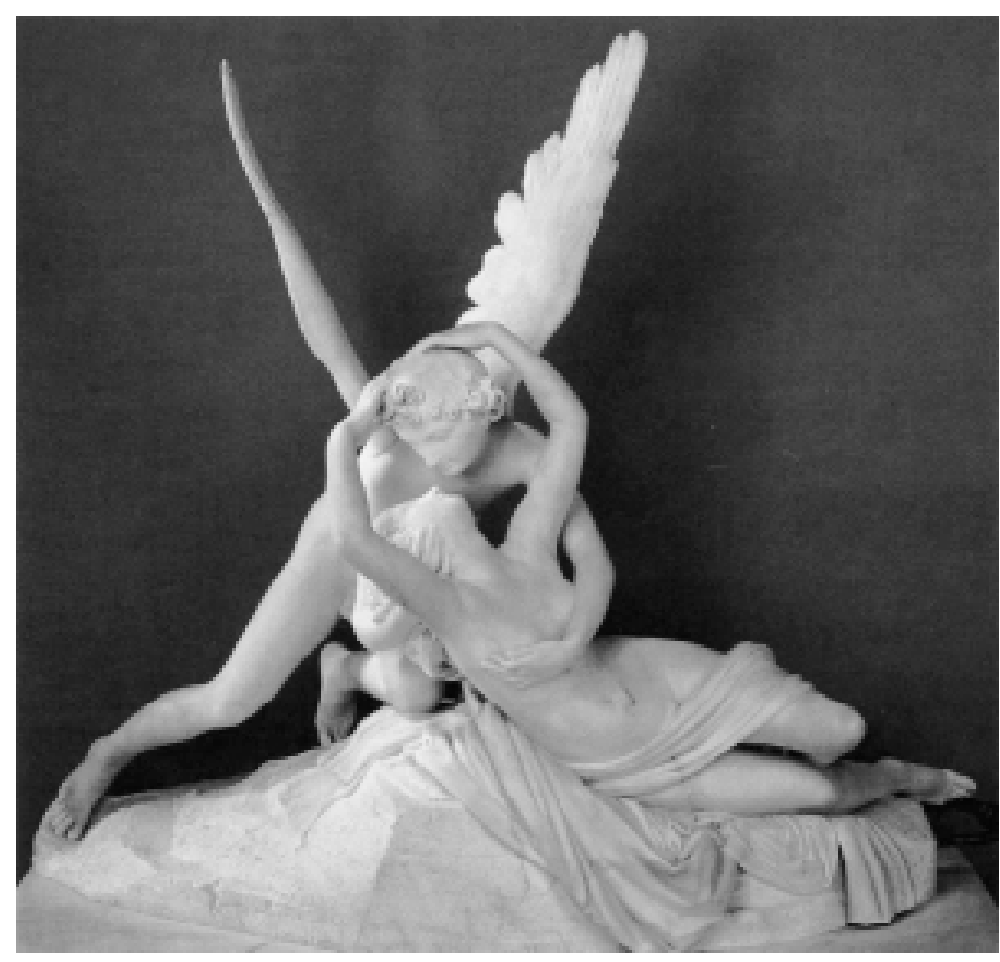

Psique y Amor

Escultura de Antonio Canova, Musée du Louvre, París 


\title{
Contenidos jurídicos en el relato de Cupido y Psique de Apuleyo
}

\author{
Martha Elena Montemayor Aceves
}

Al inicio del Digesto de Justiniano, los compiladores definen el ius, basándose en Celso: "el derecho es el arte de lo bueno y de lo justo". ${ }^{1}$ Quienes tenían autoridad de discernir entre lo justo y lo injusto eran los jurisprudentes, y sus escritos recopilados por Justiniano en su Corpus Iuris Civilis, junto con las leyes dadas por los emperadores, conforman en gran medida lo que conocemos como Derecho romano. Si bien es cierto que para su estudio es necesario acercarse a esta compilación, creo también útil, y a la vez interesante, para el mismo objetivo, acercarse a otra disciplina: la literatura. En efecto, el Derecho no surge como fenómeno aislado, sino que forma parte de una cultura que se ve reflejada en textos literarios. Mi interés es rastrear contenidos jurídicos en obras literarias, las cuales son instrumentos que nos permiten llegar al conocimiento de una sociedad, y que con frecuencia nos proporcionan información acerca de preceptos normativos, así como de otras disciplinas.

A través del presente trabajo intentaré analizar las instituciones jurídicas romanas del matrimonio y de la esclavitud, tal como se encuentran en el mito de Cupido y Psique, historia que parece dirigida a niños y que se encuentra en medio de $E l$ asno de oro o Metamorfosis de Apuleyo, obra en la que confluyen diversas disciplinas, tales como literatura, filosofía, mitología, religión y derecho.

\footnotetext{
${ }^{1}$ Ulpiano 1 Inst., en D., 1, 1, 1 pr.: ius est ars boni et aequi.
} 
Apuleyo nació en Madaura, una pequeña provincia romana de África, hacia el año 128 d. C., y murió entre el 170 y el 192, bajo el reinado de Marco Aurelio o el de Cómodo. Apuleyo es, pues, un provinciano africano del siglo II d. C.

En Cartago ${ }^{2}$ estudió gramática y retórica; en Atenas, poesía, geometría, música, ciencias naturales, medicina, dialéctica y filosofía, ${ }^{3}$ teniendo especial inclinación por las escuelas aristotélica y platónica. Se inició en diversos misterios, como los de Eleusis ${ }^{4}$ y los de Isis. ${ }^{5}$ Su talento en la oratoria lo llevó a tener éxito como conferenciante (en griego y en latín), ${ }^{6}$ a tal grado que en Cartago se convierte en el orador oficial, encargado de pronunciar los discursos laudatorios a los gobernadores en nombre de la comunidad, como el dirigido al procónsul Severiano o el panegírico a Escipión Orfito. ${ }^{7}$ También tuvo éxito en el foro; en el último libro de El asno de oro, él mismo confiesa que ejerce su profesión de abogado consiguiendo con ella fama y dinero. ${ }^{8}$

Cuando tenía cerca de 30 años, fue acusado de haber utilizado artes mágicas para casarse y, a la vez, apoderarse de la dote de Pudentila, una viuda rica. La acusación, crimen magiae, hecha por su hijastro, era grave, pues de acuerdo con la Lex Cornelia de sicariis et veneficiis, la sentencia era, según Marciano, para los humiliores ser arrojados a las bestias y, para los honestiores ser deportados a una isla. ${ }^{9}$ Apuleyo fue absuel-

\footnotetext{
${ }^{2}$ Cartago era, por esas fechas, un emporio de ciencia y cultura. En Florida, 20, Apuleyo le dedica un encendido panegírico.

${ }^{3}$ Flor., 18, 15; 20, 3 y ss.

${ }^{4}$ Apol., 55.

${ }^{5}$ Met., XI.

${ }^{6}$ Se han conservado fragmentos de estas conferencias en la antología conocida con el nombre de Florida.

${ }^{7}$ Este discurso tuvo que ser pronunciado en el 164, fecha a partir de la cual se pierden rastros de su vida.

${ }^{8}$ Met., XI, 28, 6; XI, 30, 4.

${ }_{9}^{9}$ Marciano, Inst., en D., 8, 3, 5: ... humiliores enim solent vel bestiis subici, altiores vero deportantur in insulam.
} 
to, lo cual se deduce por el discurso conservado que pronunció en su defensa: Apologia seu Pro se de magia liber. ${ }^{10}$

La historia de Cupido y Psique comienza así: Erant in quadam civitate rex et regina... ${ }^{11}$ tal como empiezan los cuentos, según la comprensión literaria occidental y moderna del relato infantil: "Había una vez, en una ciudad, un rey y una reina". Tenían tres hijas, la más pequeña de las cuales era tan hermosa como la misma Venus. Ciudadanos y forasteros la veneraban como si se tratara de la misma diosa, por lo que ésta, enfurecida, pide a su hijo Cupido venganza y castigo para la belleza contumaz (pulchritudinem contumacem). ${ }^{12} \mathrm{Su}$ petición es que esa joven sea víctima del más infamante de los amores. Psique se siente sola porque no hay rey, ni príncipe ni hombre del pueblo deseoso de pedir su mano (cupiens eius nuptiarum), ${ }^{13}$ mientras que sus hermanas ya se han casado. Como es costumbre, el padre consulta el oráculo de Apolo, el cual le dice que coloque a su hija sobre la roca de un monte, ataviada con el ajuar de un tálamo de muerte, pues el yerno con quien debe casar a su hija no es un mortal, sino un monstruo despiadado, venenoso, que, volando, todo lo aflige, y que es temido hasta por el mismo Júpiter.

Ahora bien, para que un matrimonio fuera válido en la sociedad romana se necesitaban cuatro condiciones: pubertad, consentimiento de los esposos, consentimiento del pater familias y connubium; así lo afirma Paulo: "No puede haber <justas> nupcias a no ser que consientan todos; es decir, los que se unen y aquellos bajo cuya potestad están". ${ }^{14}$ Psique

\footnotetext{
${ }^{10}$ Cf. la traducción de Roberto Heredia Correa, Apuleyo, Apología, México, Universidad Nacional Autónoma de México, 2003.

${ }^{11}$ Met., IV, 28, 1.

${ }^{12}$ Met., IV, 31, 1.

${ }^{13}$ Met., IV, 32, 1.

${ }^{14}$ Paulo, 35, Ad edictum, en D., 23, 2, 2: Nuptiae consistere non possunt nisi consentiant omnes, id est qui coeunt quorumque in potestate sunt.
} 
cumple con los tres primeros requisitos, ya está en edad de casarse, es una mulier nubilis, o viri potens y, a pesar del miedo que les causa el desconocido marido, ambos, padre e hija, consienten en que el matrimonio se lleve a cabo.

Así pues - continúa Apuleyo-, concluidas, en medio de la mayor aflicción, las ceremonias del fúnebre himeneo, es llevado en procesión aquel cadáver viviente, seguido por el pueblo entero, y Psique, deshecha en lágrimas, va camino no de sus bodas, sino de sus propias exequias. ${ }^{15}$

Ella pide que la conduzcan a la roca señalada por el oráculo y se mezcla entre la gente de la comitiva que la acompaña y lleva la antorcha nupcial, que despide negro humo, en señal de mal augurio. Según Pomponio:

se admite que la mujer pueda casarse con el ausente, o por cartas de éste o por nuncio, si fuera conducida a casa de él; pero la que está ausente... no puede casarse; pues en la conducción es necesario <ir> a la casa del marido, como si <se considerara> el domicilio del matrimonio. ${ }^{16}$

En este caso, el novio, Cupido, está ausente, y aunque no manda ni a un nuncio ni cartas, se sabe que está de acuerdo con el matrimonio. La comitiva que acompaña y conduce a la novia a la roca de la cima del monte, la cual representa la puerta de la casa del esposo, es la que correspondería a la deductio in domum mariti, donde la novia va velada y una antorcha, sostenida por un niño que personificaba al dios Himeneo, precede la comitiva.

\footnotetext{
${ }^{15}$ Met., IV, 34, 1.

${ }^{16}$ Pomp., 4 Sab., en D., 23, 2, 5: Mulierem absenti per literas eius vel per nuntium posse nubere placet, si in domum eius deduceretur: eam vero quae abesset... duci a marito non posse: deductione enim opus esse in mariti... domum, quasi in domicilium matrimonii.
} 
Sin embargo, hay una condición de validez de matrimonio que no se cumple, la del connubio; facultad legal de contraer nupcias que, según Ulpiano, la tenían "los ciudadanos romanos entre sí, con los latinos y con los extranjeros..., <pero> con los esclavos no existe connubio". ${ }^{17}$

Aunque Psique es de condición libre, no hay matrimonio legítimo pues los contrayentes no son de la misma condición, él es un dios y ella, una mortal. Por otra parte, y como veremos más adelante, Venus considera a Psique una esclava, con lo cual se ve claramente que el matrimonio es ilegítimo, ya que no puede haber matrimonio entre un libre y una esclava. Este aspecto jurídico puede ser considerado como parte de la estrategia temática de Apuleyo para sostener la intriga.

Una vez que Psique es abandonada en la roca, Céfiro la alza suavemente y la conduce a un palacio. Una voz sin cuerpo le dice que todo es suyo, que descanse, que se bañe y que coma. Por la noche, en el lecho, estaba su misterioso marido (ignobilis maritus), ${ }^{18}$ al cual ella no puede ver. Él la hace su esposa y se retira antes de rayar el alba. Así, sin ver Psique el rostro ni el cuerpo de su esposo, transcurrieron las cosas durante mucho tiempo.

Las hermanas, quienes no son felices con sus maridos extranjeros, uno calvo y viejo, el otro encorvado por la artritis, sienten envidia de la suerte y riquezas de Psique. Cupido le advierte que ellas le causarán una tremenda desgracia, y que nunca intente descubrir la apariencia de su marido, pues podría perder sus abrazos $\mathrm{y}$, además, le revela que su vientre lleva dentro de sí un hijo. A pesar de todas las advertencias, Psique escucha a sus hermanas, quienes le aconsejan un plan:

\footnotetext{
${ }^{17}$ Reglas de Ulpiano (EpUlp.), V, 4 y 5: Conubium habent cives Romani cum civibus Romanis: cum Latinis autem et peregrinis... Cum servis nullum est conubium.

${ }^{18}$ Met., V, 4, 3.
} 
esconde (absconde) en el lecho... una navaja filosa (novaculam praeacutam)..., y pon debajo una lámpara llena de aceite (lucernamque completam oleo subde)..., cuando él esté dormido... liberas la lámpara de su cárcel... y, alzando tu brazo... descarga audazmente un fuerte golpe y corta el nudo que une a la cabeza de funesta serpiente < pues ellas le han hecho creer que el esposo es una serpiente $>.{ }^{19}$

Pero cuando Psique lleva a cabo el plan, gracias a la luz ve, en vez de una horrenda serpiente, a la más delicada y la más dulce de todas las fieras, a Cupido mismo en persona. Entonces

la luz de la lámpara se aviva regocijada y la navaja se arrepiente de su sacrílego filo... Psique ve la rubia cabellera... impregnada de ambrosía; ve su cabello en bucles graciosamente enmarañados cayéndole en cascada sobre su cuello... En la espalda del dios volador, las plumas resplandecen de blancura... ${ }^{20}$

Psique lo contempla con admiración y, curiosa, extrae del carcaj una flecha, con la cual, sin darse cuenta se hiere el dedo, y así, por sí misma, cae enamorada del Amor. En tal contemplación, ella deja caer de la lámpara una gota de aceite hirviendo sobre el hombro del dios. Éste, viéndose mancillado, sale volando sin decir palabra. Ella se queda contemplando el vuelo de su esposo, afligiendo su corazón con extremas lamentaciones.

Luego, Psique abandona el palacio y, errante, llega a la ciudad donde habitaba una de sus hermanas, a quien le miente diciéndole:

...en cuanto pude contemplar su rostro a la luz de la lámpara... Mi esposo, despertándose bruscamente, me dijo: "Tú ciertamente por este crimen (facinus) tan horrendo aléjate (divorte) inmediatamente de mi lecho y ten tus cosas (tibi res tuas habeto). Yo,

${ }^{19}$ Met., V, 20, 5.

${ }^{20}$ Met., V, 22, 2-6. 


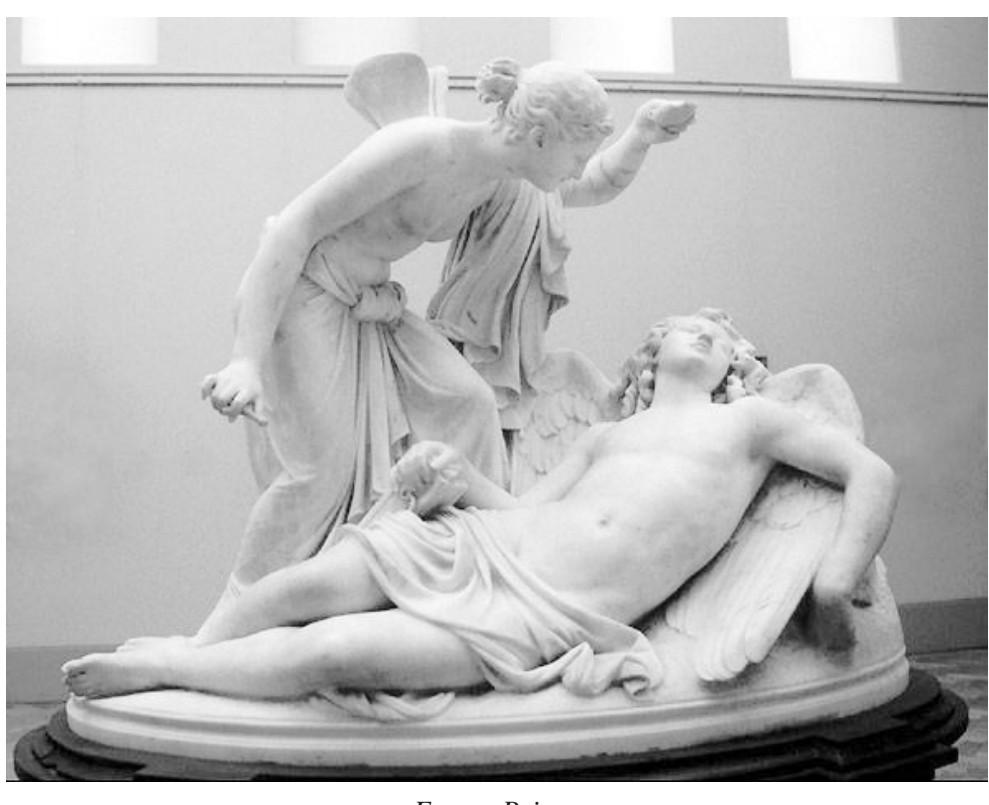

Eros y Psique

Escultura de Reinhold Begas, Altes Museum, Berlín

en verdad, es con tu hermana... con la que me voy a casar por confarreatio (confarreatis nuptis coniugabo)". ${ }^{21}$

Apuleyo utiliza el verbo divorto (alejarse de), del que se deriva la palabra divorcio, y hace alusión, literalmente, a la fórmula del repudio que se cita en el Digesto: "tuas res tibi habeto". ${ }^{22}$ En cuanto al supuesto casamiento con la hermana, se refiere a la confarreatio, la cual es un modo de adquisición de la manus de la esposa. Ulpiano la define de este modo:

${ }^{21}$ Met., V, 26, 7: Tu quidem, inquit, ob istud tam dirum facinus confestim toro meo divorte tibique res tuas habeto, ego vero sororem tuam... iam mihi confarreatis nuptis coniugabo.

${ }^{22}$ Gai., 11, ed. prov., en D., 24, 2, 1: In repudiis autem, id est renuntiatione comprobata sunt haec verba: "tuas res tibi habeto", item haec: "tuas res tibi agito" (Pero en los repudios, esto es, en el anuncio, se aprueban estas palabras: "ten tus cosas para ti", e igualmente éstas: "llévate tus cosas para ti"). 
"queda bajo la potestad del marido mediante el pan de trigo, con determinadas palabras, con diez testigos presentes y celebrando un solemne sacrificio, en el cual se ofrece el pan fárreo". ${ }^{23}$ Gayo especifica que el solemne sacrificio es en honor del dios Júpiter Fárreo, y que los sacerdotes mayores, los de Júpiter, Marte y Quirino, no pueden ser elegidos si no han nacido de un matrimonio en el que se haya celebrado este acto. ${ }^{24}$ En realidad, esta forma de adquirir la manus estaba reservada para los patricios $\mathrm{y}$, a finales de la república, su celebración es rara; sin embargo, hay que hacer notar que Apuleyo, escritor africano del siglo II d. C., aún la menciona, lo cual, además, podría suponer que dicha forma de casamiento se difundió en todo el imperio.

La hermana de Psique, al oír tales palabras, agitada por una loca pasión, se dirige inmediatamente a la roca. Confiando en que Céfiro la transportaría, se precipita al vacío, y muere ofreciendo a las aves rapaces un festín con sus miembros descuartizados. La otra hermana tuvo el mismo castigo.

En la segunda parte de la historia (Met., VI), Psique pretende suavizar la ira de Cupido ya no con las caricias de una esposa (uxoriis blanditiis), sino con las súplicas de una esclava (servilibus precibus), por lo que ella misma cambia su personalidad jurídica; podríamos decir que sufre una capitis deminutio maxima. Sin embargo, como esclava no pertenece a Cupido, un dominus, sino a una domina, la diosa Venus, su suegra, quien está furiosa por la unión de su hijo con ella. ${ }^{25}$

Psique, vagando en busca de su esposo, llega al templo de la diosa Ceres, a quien, arrojándose a sus pies, le pide que le

\footnotetext{
${ }^{23}$ EpUlp., 9, 1: Farreo convenitur in manum certis verbis et testibus $X$ praesentibus et sollemni sacrificio facto, in quo panis quoque farreus adhibetur.

${ }^{24}$ Gai., $1,112$.

${ }^{25}$ La alegoría de Psique como esclava podría significar que ella se convierte en la esclava del amor. En esa consideración, es Venus quien, por las circunstancias, se convierte en su domina.
} 
permita ocultarse por unos pocos días hasta que se mitigue la cólera de Venus, a lo que Ceres responde que no puede ponerse en mal con quien es su pariente. Le dice: "Sal, pues, inmediatamente de mi casa y considérate bien pagada por no haberte retenido y guardado entre rejas". ${ }^{26}$ Psique se va afligida y llega al templo de Juno, a quien le suplica como embarazada, pues Juno Lucina es la protectora de las embarazadas. Sin embargo, esta diosa se niega a ayudarla porque no puede hacer algo que vaya en contra de su nuera. ${ }^{27} \mathrm{Y}$ agrega: "me veo impedida incluso por las leyes que prohíben dar acogida, contra la voluntad de sus dueños, a los esclavos fugitivos". ${ }^{28}$

Apuleyo refleja aquí varias características de los esclavos, las cuales están especificadas por Ulpiano: "se considera fugitivo también si es vagabundo". ${ }^{29}$ Al vagar en busca de su esposo, y huir de la cólera de Venus, su domina, Psique se convierte en una esclava fugitiva y ni Ceres ni Juno la pueden ayudar, pues la ley señala, de acuerdo con Ulpiano, que "quien oculta a un esclavo fugitivo es un ladrón", ${ }^{30}$ y que quien comete este delito estará condenado a pagar "una multa de cien sueldos". ${ }^{31} \mathrm{El}$ esclavo fugitivo, a su vez, puede ser castigado severamente rapándole la cabeza y las cejas, y marcándole en la frente con hierro candente un signo o letra, por ejemplo, $\mathrm{F}$ de fugitivo. ${ }^{32}$

Cuando Ceres la despide y le dice: "considérate bien pagada por no haberte retenido y guardado entre rejas", Apuleyo se está refiriendo al rescripto ${ }^{33}$ de Marco Aurelio y Cómodo:

\footnotetext{
${ }^{26}$ Met., VI, 3, 1.

${ }^{27}$ Es decir, Venus, la esposa de su hijo Vulcano.

${ }^{28}$ Met., VI, 4, 5.

${ }^{29}$ D., 11, 4, 1, 5: Fugitivum accipe et si quis erro sit.

${ }^{30}$ Ulp., en D., 11, 4, 1: Is qui fugitivum celavit fur est.

${ }^{31}$ D., 11, 4, 1, 2: ...multa etiam centum solidorum.

32 Petronio, Sat., 103, n. 1, versión de Roberto Heredia. Cf. Quintiliano, VI, 4, 14; Valerio Máximo, VI, 8, 7; Ausonio, Epig., XV, 3, y Juvenal, XIV, 24.

${ }^{33}$ Los rescriptos eran respuestas que el emperador daba por escrito a magistrados o a particulares, sobre cuestiones jurídicas. Tenían fuerza de ley.
} 
"La custodia diligente permite también tenerlos prisioneros", 34 es decir, Ceres hubiera podido retenerla como prisionera para después entregarla a su domina, según lo establecía este rescripto.

También cita éste cuando Juno explica: "me veo impedida incluso por las leyes que prohíben dar acogida, contra la voluntad de sus dueños, a los esclavos fugitivos", prescripción que encontramos en el Digesto: "se debe ayudar al dueño en la búsqueda de sus esclavos... y... serán castigados aquellos en cuyas casas se oculten". ${ }^{35}$ Juno estaba obligada, por la ley, a ayudar a Venus en la búsqueda de Psique; si no lo hacía, podría ser castigada a pagar una multa.

Venus, para encontrar a la esclava fugitiva, solicita, con la aprobación de Júpiter, la ayuda de Mercurio, a quien le ordena: “...haz saber a todo el mundo las señales (indicia) que pueden ayudar a un reconocimiento perfecto para que nadie, si se le acusa de una ocultación indebida, pueda alegar, en su defensa, la excusa de ignorancia". ${ }^{36} \mathrm{Al}$ respecto, Ulpiano apunta: "...están bajo custodia hasta que... se comuniquen a los magistrados sus nombres y señales... a fin de que puedan más fácilmente ser reconocidos y recuperados... (en la palabra 'señales' se comprenden también las cicatrices)". ${ }^{37}$

Por la naturaleza de la recompensa que ofrece Venus, siete besos y uno, pura miel, con la punta de la lengua, Psique se da cuenta de que no podrá seguir ocultándose, y decide presentarse ante su misma domina quien, furiosa, le hace varios señalamientos jurídicos: la unión entre ella y Cupido es ilegítima, pues "las nupcias son desiguales (impares nuptias)"; es decir, como mencioné antes, los contrayentes no son de la misma

\footnotetext{
${ }^{34}$ D., 11, 4, 1, 7: Diligens custodia etiam vincire permittit.

35 D., 11, 4, 1: ...dominum adiuvare debere inquirendis fugitivis... et... hi, apud quos delitescant puniantur...

${ }^{36}$ Met., VI, 7, 5.

${ }^{37}$ D., $11,4,8^{\text {a }}$ : notae autem verbo etiam cicatrices continentur...
} 
clase, ella es esclava y él es un Dios; "además — continúa- no se consideran legítimas las nupcias celebradas en una villa sin testigos y sin consentimiento del padre", se refiere también al desacuerdo de la misma diosa, madre de Cupido, ${ }^{38}$ y al palacio en donde nadie habita y sólo se oyen voces; "y por ello — sigue diciéndole-, éste [se refiere al hijo que espera] cuando nazca, será bastardo". ${ }^{39}$ Así pues, la hija que nacerá (porque será niña) siendo Psique esclava, seguirá la condición de la madre y será espuria, pero si nace siendo ella libre, seguirá la condición del padre.

Venus le impondrá cuatro pruebas a Psique antes de admitirla como nuera, ${ }^{40}$ que podrían interpretarse como las penalidades que sufre el alma humana en busca del amor: la primera consiste en separar granos; la segunda, en llevarle un copo del vellón de oro de ciertas ovejas que suelen ser presa de una rabia tan feroz que matan a los seres humanos; la tercera, en llenar una jarra de agua de una tenebrosa fuente custodiada por serpientes; y la última es la de bajar al Hades y entregarle una cajita, la cual no debe abrir, a Proserpina para que le dé un poco de su hermosura. Psique cumple con todas las pruebas, y como ella había sido piadosa para con los dioses, éstos, en reciprocidad, la ayudan mediante la Providencia. Este concepto designa la actitud benévola de los dioses, la cual se presenta en forma de un ejército de hormigas, de una caña o de una torre. Pero el mayor defecto de Psique, que ya la había perdido antes, es la curiosidad; así que después de cumplir su última tarea y de recibir el don de Proserpina, abre la caja, y lo que sale no es la hermosura, sino el sueño infernal, que la deja como un cadáver durmiente (dormiens cadaver). Cupido,

\footnotetext{
${ }^{38}$ Cf. nota 41.

${ }^{39}$ Met., VI, 9, 6: et praeterea in villa sine testibus et patre non consentiente factae legitimae non possunt videri ac per hoc spurius iste nascetur...

${ }^{40}$ Estas pruebas impuestas por una hechicera, madrastra, rey o reina, es un tema recurrente en el cuento fantástico, recuérdense los trabajos de Hércules.
} 
como no puede soportar la ausencia de su querida Psique, escapa de la casa de su madre, llega volando hasta ella, disipado el sueño (deterso somno), lo vuelve a encerrar en la caja $y$, con la punta de una de sus flechas, la despierta. ${ }^{41}$

Al final de la historia, Apuleyo muestra sus dotes de literato y abogado, haciendo una parodia del Derecho romano. Cupido "suplica a Júpiter y defiende su propia causa" (Iovi supplicat suamque causam probat). ${ }^{42}$ Júpiter, llamándolo "hijo y señor" (domine filii), ${ }^{43}$ le recrimina las constantes heridas que le hace a su corazón, orillándolo a cometer torpes adulterios, actuando en contra de la Lex Iulia de adulteriis. ${ }^{44}$ Enseguida, Júpiter ordena a Mercurio que convoque a todos los dioses para anunciar la boda de Cupido y Psique; y que si alguno falta, tendrá que pagar 10 mil sestercios de multa. El dios inicia la asamblea como si fuera el emperador que se dirige al Senado y, en vez de decir "Padres conscriptos", los llama

Oh Dioses conscriptos, registrados en las listas de las musas ( $d e i$ conscripti Musarum albo $)^{45} \ldots$ - prosigue-, los ímpetus de su juventud <se refiere a Cupido> deben ser reprimidos mediante un freno. Ya está bien que todo el mundo... ande desacreditando su reputación a causa de sus adulterios... Él ha elegido una mu-

\footnotetext{
${ }^{41}$ Met., VI, 21.

${ }^{42}$ Met., VI, 22, 1.

${ }^{43}$ Met., VI, 22, 3. En la tradición más común, Mercurio es el padre de Cupido. Pero Apuleyo no recoge esta tradición y tampoco aclara quién es el padre. En varios pasajes hace alusión a este tema: cuando Venus alega que el matrimonio es ilegítimo porque se hizo "sin el consentimiento del padre" (VI, 9, 6); cuando Júpiter dice que Cupido ha crecido entre sus manos (VI, 22, 5), y que lo ha criado entre sus manos (VI, 23, 2). Júpiter considera a Cupido como hijo, por ser el hijo de su hija Venus.

${ }^{44}$ Promulgada por Augusto en el 17 a. C.

${ }^{45}$ Met., VI, 23, 2. Los censores tenían el album senatorum; el de los dioses lo tenían las Musas, lo que podría significar que son los escritos de los poetas, a los que los dioses deben su fama. Cfr. Vallette, p. 92, n. 1. (Ver Apulée, Les Métamorphoses, en la Bibliografía.)
} 
chacha... que se quede con ella, que sea su dueño (teneat, possideat)... Yo haré que las nupcias no sean desiguales, sino legítimas de acuerdo con el Derecho civil (Iam faxo nupcias non impares sed legitimas et iure civili congruas)... Y, ofreciéndole una copa de ambrosía, le dice: "Psique, sé inmortal..., y vuestro matrimonio será un matrimonio indisoluble"... Así Psique, de acuerdo con la costumbre, entró bajo la potestad marital (Sic rite Psyche convenit in manum Cupidinis) y, cumplido el tiempo del embarazo, les nació una hija a la que llamamos Voluptuosidad (quam Voluptatem nominamus). ${ }^{46}$

Con la expresión convenit in manum, Apuleyo nos indica la forma de matrimonio en la que Psique queda bajo la manus de Cupido, es decir, queda bajo la potestad de su marido, en el lugar de una hija (loco filiae). ${ }^{47}$ Las nupcias serán legítimas de acuerdo con el Derecho civil, porque Júpiter hace inmortal a Psique, y así los dos contrayentes están en la misma situación jurídica. La hija que les nace, por lo tanto, sigue la condición del padre, así pues, Voluptas es una diosa.

En suma, las instituciones jurídicas romanas del matrimonio y la esclavitud, mostradas a través de conceptos como la deductio in domum maritii, la conventio in manum, la confarreatio, el repudium, el hijo spurius, el servus fugitivus y las leyes que lo castigan a él y a quienes lo protegen, extraídas de un rescripto de los emperadores Marco Aurelio y Cómodo, nos muestran el amplio conocimiento que Apuleyo tenía del Derecho romano, el cual se deriva de su profesión de abogado. Sin embargo, lo más significativo que he querido resaltar en este trabajo es la aplicación que el autor hace de sus conocimientos jurídicos en una obra literaria tan bellamente narrada, en la que podemos

\footnotetext{
${ }^{46}$ Met., VI, 23 y 24.

${ }^{47} \mathrm{La}$ conventio in manum era la forma en que la mujer casada entraba bajo la potestad de la familia del marido. Esta entrada se podía dar de tres maneras: por confarreatio, coemptio o usus. Recuérdese que Apuleyo ya hizo referencia anteriormente a la confarreatio.
} 
apreciar el Derecho de una manera concreta, real y tangible, aplicando las leyes a la sociedad y a la cultura de su época.

\section{BIBLIOGRAFÍA}

Albrecht, Michael von, Historia de la literatura romana, t. II, Barcelona, Herder, 1999.

Apulée, Apologie-Florides, trad. Paul Vallette, Paris, Les Belles Lettres, 1971.

—, Les Métamorphoses, t. I, II, trad. Paul Vallette, Paris, Les Belles Lettres, 1976.

Apuleyo, Apología o Discurso sobre la Magia en defensa propia, vrs. Roberto Heredia Correa, México, Universidad Nacional Autónoma de México (Bibliotheca Scriptorum Graecorum et Romanorum Mexicana), 2003.

—, El asno de oro, Pejenaute Rubio (ed.), Barcelona, Ediciones Akal, 1988.

D’Ors, Álvaro, Derecho privado romano, Pamplona, Ediciones Universidad de Navarra, 1997 ( $9^{\mathrm{a}}$ ed.).

El Digesto de Justiniano, 3 vols., trad. Álvaro d'Ors et al., Pamplona, Editorial Aranzadi, 1968-1975.

Gayo, Instituciones, Fco. Hernández Tejero (coord.), Madrid, Editorial Civitas, 1985.

Guillén, José, Vrbs Roma, vida y costumbres de los romanos, t. 1 La vida privada, Salamanca, Ediciones Sígueme, 1981.

Iustiniani Digesta, Corpus Iuris Civilis, I, Theodor Mommsen (ed.), Dublín, Weidmann, 1963.

Mora, Patricia, y Jorge Porto, "La usura en Roma en tiempos de Plauto", XIV Congreso Latinoamericano de Derecho Romano, Buenos Aires, 2004.

Padilla Sahagún, Gumesindo, Derecho Romano, México, McGraw-Hill (Serie Jurídica), 2004 ( $3^{\mathrm{a}}$ ed.).

Petronio, Satiricón, vrs. Roberto Heredia Correa, México, Universidad Nacional Autónoma de México (Bibliotheca Scriptorum Graecorum et Romanorum Mexicana), 1997.

RABinovich-Berkman, Ricardo, "La escalinata de los lamentos, ¿evidencias de suplicios rituales en Roma? (a partir de sendos poemas de Catulo y Ovidio)", XIV Congreso Latinoamericano de Derecho Romano, Buenos Aires, 2004. 
Reglas de Ulpiano, trad. Fco. Hernández Tejero, Madrid, Ministerio de Justicia y Consejo Superior de Investigaciones Científicas, 1946.

SuÁrez, Marcela, "Interdicitio aqua et ignis o la ciudadanía en Jaque (P1., Aul., 85-100)", XIV Congreso Latinoamericano de Derecho Romano, Buenos Aires, 2004.

Villaseñor, Patricia, “Apuleyo, filósofo y mago", Acta Poética, 17, primavera de 1996, pp. 53-69. 
